\title{
Tadalafil-Loaded Limonene-Based Orodispersible Tablets: Formulation, in vitro Characterization and in vivo Appraisal of Gastroprotective Activity
}

This article was published in the following Dove Press journal: International Journal of Nanomedicine

Mohammed M Mehanna (D) ${ }^{1,2}$ Amina Tarek Mneimneh ${ }^{2}$ Souraya Domiati ${ }^{3}$ Ahmed N Allam ${ }^{4}$

'Department of Industrial Pharmacy, Faculty of Pharmacy, Alexandria University, Alexandria, Egypt;

${ }^{2}$ Department of Pharmaceutical Technology, Faculty of Pharmacy, Beirut Arab University, Beirut, Lebanon; ${ }^{3}$ Department of Pharmacology and Therapeutics, Faculty of Pharmacy, Beirut Arab University, Beirut, Lebanon; ${ }^{4}$ Department of Pharmaceutics, Faculty of Pharmacy, Alexandria University, Alexandria, Egypt
Correspondence: Mohammed M Mehanna

Department of Pharmaceutical Technology, Faculty of Pharmacy, Beirut Arab University, Beirut, Lebanon Tel +961 71708661

Email mmhanna@bau.edu.lb
Background: Gastric ulcer is a prevalent disease with various etiologies, including nonsteroidal anti-inflammatory drugs and alcohol consumption. This study aimed to explore the dual gastric protection effect of tadalafil and limonene as a self-nanoemulsifying system (SNES)-based orodispersible tablets.

Methods: Tadalafil-loaded limonene-based SNES was prepared, and the optimum formula was characterized in terms of particle size (PS), polydispersity index (PDI), and zeta potential (ZP) then loaded on various porous carriers to formulate lyophilized orodispersible tablets (ODTs). The ODTs were evaluated via determining hardness, friability, content uniformity, wetting, and disintegration time. The selected ODT was examined for its gastric ulcer protective effect against alcohol-induced ulcers in rat model. Ulcer score and ulcer index were computed for rats stomachs that were inspected macroscopically and histopathologically.

Results: The prepared SNES had droplet size of $104 \mathrm{~nm}$, polydispersity index of 0.2 , and zeta potential of $-15.4 \mathrm{mV}$. From the different ODTs formulated, the formula with superior wetting time: $23.67 \mathrm{~s}$, outstanding disintegration time: $28 \mathrm{~s}$, accepted hardness value: $3.11 \mathrm{~kg} / \mathrm{cm}^{2}$ and friability: $0.6 \%$ was designated. A significant gastroprotective effect of the unloaded and tadalafil-loaded ODTs was recognized compared to the omeprazole pretreated group. Moreover, the histopathological analysis displayed very mild inflammation in the limonene-based ODTs group and intact structure in the tadalafil-loaded pre-treated animals.

Conclusion: Limonene gastroprotective effect functioned along with tadalafil in the form of SNES-incorporated ODTs could serve as a promising revenue for better efficacy in gastric ulcer prevention.

Keywords: gastric ulcer, gastroprotection, limonene, orodispersible tablets, selfnanoemulsifying system, tadalafil

\section{Introduction}

Gastric mucosal damage is the most common disorder of the gastrointestinal system. ${ }^{1}$ This damage is due to the disequilibrium between destructive and protective factors, resulting in the breaking of the gastric mucosal layer leading to ulcer formation. ${ }^{2}$ Hemorrhage or gastric bleeding is the most frequent complication of gastric ulcer and its prevalence is increasing compared to perforation and stenosis where $60 \%$ of the perforated gastric ulcer is located in the duodenum followed by $23 \%$ in the pyloric region and $17 \%$ in the gastric area. ${ }^{3}$ The ulcerogenic factors are 
mucosal hypoperfusion, gastric hydrochloric acid, oxygenfree radicals, Helicobacter pylori infection, excessive intake of non-steroidal anti-inflammatory drugs (NSAIDs), $50 \%$ of patients who administer NSAIDs are beyond 60 years, ${ }^{4}$ and ethanol intake which induces gastric mucosal damage and gastric ulceration. As for the mucosal defense mechanisms, they include; secretion of bicarbonate and mucosal blood supply. Additionally, lifestyle and digestive disorders have been linked as risk factors (or cofactors) together that can worsen gastrointestinal performance and aggravate peptic ulcer, such dietary habits as smoking, alcohol consumption, and psychological stress. Alcohol intake increases the risk of bleeding in patients with peptic ulcers and should be avoided by people who have ulcers or at high risk. ${ }^{5}$

Treating gastric ulcers is a medical challenge, as it encounters several constraints, namely limited efficacy of the available drugs, side effects, and refractory ulcer. ${ }^{6}$ Refractory ulcers (ulcers that did not heal within 8-12 weeks) can be due to bacterial resistance to the regimen, patient non-compliance, smoking, alcohol consumption, Zollinger-Ellison syndrome, and uncontrolled use of NSAIDs. ${ }^{7}$ Although conventional proton pump inhibitors (PPIs) are the first-line treatment for gastric ulcers and were considered safe, yet, these drugs possess some adverse effects on long-term use, such as Clostridium difficile-associated diarrhea, pneumonia, stroke, and fracture risk. ${ }^{8}$ Finding from a prospective analysis suggested that the long-term use of PPIs is associated with osteoporotic fractures, especially in postmenopausal women. ${ }^{9}$ A case-control study on patients in the United Kingdom showed that there is an increased risk of hip fracture among patients on long-term (more than 1 year) and high dose PPIs, ${ }^{10}$ and another crossover study on elderly women aging $\geq 65$ years receiving omeprazole as PPI confirmed that after 14 days of the PPI treatment an average $41 \%$ decrease in calcium absorption from calcium carbonate occurred. ${ }^{11}$ All of these factors create a need to design a more effective and superior therapeutic protocol to treat and prevent the recurrence of peptic ulcers. From this point, healthcare seekers supported the use of herbal ingredients in the management of GIT disorders. ${ }^{12}$ For example, D-limonene is a monoterpene found in the essential oil of the citrus fruit peels of several Rutaceae species. This oil possesses a gastroprotective effect against ethanoland NSAID-induced gastric ulcer, and Helicobacter pylori infection. ${ }^{13}$ In addition to the natural remedies, phosphodiesterase (PDE-5) inhibitors such as tadalafil, sildenafil, and vardenafil, based on their mechanism of action, can be employed in the treatment of other conditions than their urological use. ${ }^{14,15}$ Kolawole and Francis proved that tadalafil had a dose-dependent ulcer reducing effect similar to that of cimetidine against indomethacin-induced ulcers in rats. ${ }^{16}$ PDE-5 inhibitors prevent the hydrolytic degradation of cyclic adenosine monophosphate (cAMP) and/or cyclic guanosine monophosphate (cGMP), which increases cGMP level and release of endogenous nitric oxide in the GIT promoting ulcer healing. ${ }^{17}$ Since PDE-5 inhibitors are characterized by low solubility, nano-formulations are suggested approaches not only to enhance the stability and solubility of lipophilic agents but also to improve their bioavailability. Among the promising approaches to improve the rate and extent of absorption and hence the oral bioavailability of lipophilic drugs is selfnanoemulsifying drug delivery systems (SNEDDS). These systems allow drugs to circumnavigate the firstpass effect, inhibit cellular efflux mechanisms, additionally to protect drugs from degradation by GI environment.

Geriatric patients face administration and swallowing problems due to multiple medications, which are taken many times throughout the day. As there is a high demand for patient-friendly preparations, the development of innovative dosage forms has been increasing, exemplified by the emerging of ODTs that is also known as orally disintegrating tablets. These "melt-in-mouth" tablets offer rapid dissolving once placed on the tongue without the need for water, releasing the drug before swallowing. It is assumed that the convenience and the easy use of ODTs are highly preferred by some groups, mainly pediatrics, elderly, or patients with swallowing difficulties. ${ }^{18}$ The development of self-nanoemulsifying lyophilized tablets ODTs produced by freeze-drying displayed the most rapid disintegration time due to their high porosity system and is expected to improve the bioavailability and therapeutic efficacy of many drugs. ${ }^{19,20}$ As rapid drug pre-gastric absorption occurs, faster onset of action takes place with enhanced bioavailability and therapeutic outcomes, in addition to reduced dosing and adverse effects. ${ }^{21}$

The present study aims to formulate an effective and patient-friendly ODTs preparation combining the benefits of tadalafil and limonene as gastroprotective agents especially in geriatric patients. To overcome the poor solubility of tadalafil, tadalafil-loaded limonene-based SNESs were optimized by assessing its physicochemical properties viz., droplet size, zeta potential, and polydispersity index. The prepared tadalafil-loaded ODT was evaluated by its 
physical properties, including hardness, percentage friability, thickness, and content uniformity. Besides, disintegration time, wetting time, water absorption ratio, and in-vitro dissolution were examined. The gastroprotective effect of the tadalafil-loaded ODT was tested in-vivo in an experimental rat model. The gastroprotective effect was evaluated by determining the ulcer score, ulcer index, and protection percentage, in addition to the histopathological examination of the gastric mucosa.

\section{Materials and Methods \\ Chemicals and Excipients}

Tadalafil $\geq 98 \% \quad(\operatorname{Lot} \# 171,596-29-5)$ and $(\mathrm{R})-(+)$ Limonene $\sim 90 \%$ (Lot\# BCBZ1768), propylene glycol 98\% (Lot\#10,188,904), PEG-40 hydrogenated castor oil (Cremophor ${ }^{\circledR}$ RH40) $~ 98.2 \%$ (Lot \# 61,791-12-6), polyethylene glycol 400 (PEG 400) $\quad 98 \%$ (Lot\#25,322-68-3), silica (Syloid ${ }^{\circledR}$ XDP 3050) 99.6\% (Lot\# 7631-86-9), Lactose (Lot\# 64,044-51-5), microcrystalline cellulose EP (Avicel ${ }^{\circledR}$ PH-101) (Lot\# 9004-34-6), gelatin EP (Lot\#9000-70-8), glycerol $\geq 99.0 \% \quad$ (Lot\# 56-81-5), sodium starch glycolate (EXPLOTAB $^{\circledR}$ ) 98\% (Lot\# 9063-38-1), hydroxypropyl methylcellulose (HPMC k4) 99\% (Lot\# 9004-65-3) and pregelatinized starch $\sim 99 \%$ (Lot\# 1,012,520,100) were purchased from Sigma-Aldrich, Steinheim, Switzerland. PEG-8 Caprylic/capric glycerides $\left(\right.$ Labrasol $\left.^{\circledR}\right)$ (Lot\#175,459), Tween ${ }^{\circledR} 80$ (Lot\# 9005-656), oleoyl polyoxyl-6 glycerides (Labrafil ${ }^{\circledR} \mathrm{M} 1944 \mathrm{CS}$ ) (Lot\#177,032), Diethylene glycol monoethyl ether (Transcutol ${ }^{\circledR}$ HP) (Lot\# 111-90-0) were kindly donated by Gattefosse Co. (Lyon, France). All other reagents and solvents used were of analytical grade.

\section{Solubility Studies}

An excess amount of tadalafil was added to $2 \mathrm{~mL}$ of the previously optimized limonene-based SNES at a 5:4:1 ratio (limonene: Tween ${ }^{\circledR} 80$ : propylene glycol, respectively) in $5 \mathrm{~mL}$ vials. ${ }^{22}$ The vials were shaken in a controlled mechanical shaker (FALC, WB-MF24, Treviglio (BG) - Italy) at $25 \pm 2^{\circ} \mathrm{C}$ for $24 \mathrm{~h}$. The mixtures were allowed to stand for equilibrium for another $24 \mathrm{~h}$, followed by centrifugation at $5000 \mathrm{rpm}$ (Sigma 3-30KS centrifugation - Germany) for $20 \mathrm{~min}$. Tadalafil content in the supernatant was assessed spectrophotometrically (Jasco V-730 spectrophotometer, UK) at $\lambda_{\max } 291 \mathrm{~nm}$.
The experiment was carried out in triplicate and results were expressed as a mean \pm standard deviation (SD).

\section{Preparation of Tadalafil-Loaded Limonene-Based SNES}

The optimized SNES formulation is composed of limonene oil $(50 \% \mathrm{w} / \mathrm{w})$, Tween ${ }^{\circledR} 80$ as a surfactant $(40 \% \mathrm{w} / \mathrm{w})$, and propylene glycol as co-surfactant $(10 \% \mathrm{w} / \mathrm{w})$ was used for the preparation of tadalafil-loaded limonene-based SNES. ${ }^{22}$ Briefly, tadalafil was added to the prepared limonene SNES at a concentration of $5 \mathrm{mg} / \mathrm{mL}$ and the dispersion was performed for $45 \mathrm{~min}$ at $45 \pm 2{ }^{\circ} \mathrm{C}$, and then stored in sealed glass vials for further investigations.

\section{Evaluation of Tadalafil-Loaded Limonene-Based SNES Percentage Transmittance}

Percentage of transmittance was measured to evaluate the clarity of the prepared nanoemulsion after dilution with $100 \mathrm{~mL}$ deionized water, using Jasco V-730 spectrophotometer at $638.2 \mathrm{~nm}$ against water as blank. ${ }^{23}$

\section{Self-Emulsification Time}

Self-emulsification time and emulsification efficiency were assessed according to the method represented by Beg et al, the self-emulsification process was visually assessed and the time for self-emulsification was recorded. ${ }^{24}$

\section{Stability Against Different Media}

Tadalafil-loaded limonene-based SNES stability in different dissolution media was assessed by 50,100 and 1000 dilutions with deionized water, phosphate buffer ( $\mathrm{pH} 7.4)$, and $0.1 \mathrm{~N}$ $\mathrm{HCl}(\mathrm{pH}$ 1.2). The diluted nanoemulsions were stored for $12 \mathrm{~h}$ and visually inspected for any signs of physical changes such as precipitation or phase separation. ${ }^{25}$

\section{Cloud Point}

The loaded SNES was diluted with deionized water (1:100), and placed in a water bath, while the temperature was gradually increased at a rate of $1{ }^{\circ} \mathrm{C} / \mathrm{min}$ to determine the cloud point which is decided when the percentage transmittance (measured spectrophotometrically at $638.2 \mathrm{~nm}$ ) decreases.

\section{Thermodynamic Stability}

Tadalafil-loaded limonene-based nanoemulsion was diluted with $100 \mathrm{~mL}$ deionized water and centrifuged at $5000 \mathrm{rpm}$ (Sigma 3-30KS centrifugation, Germany), for $30 \mathrm{~min}$ to detect any changes in its homogeneity. Moreover, six cycles of freeze-thawing were performed. 
The formulation was stored at two different temperatures $\left(4^{\circ} \mathrm{C} \pm 0.5\right.$ and $\left.25^{\circ} \mathrm{C} \pm 2\right)$ for $24 \mathrm{~h}$ at each temperature. ${ }^{26}$ The formulation that does not show any changes in its physicochemical properties is considered successful.

\section{Physicochemical Characteristics of Tadalafil-Loaded Limonene-Based SNES}

Droplet size, zeta potential, and PDI were measured at 25 $\pm 2^{\circ} \mathrm{C}$ and $90^{\circ}$ scattering angle by Zeta sizer 2000 (Malvern Instruments, UK) after dilution with deionized water (1:100 $\mathrm{v} / \mathrm{v}) .{ }^{27}$ The above-mentioned characteristics were measured for the freshly prepared formula and the formula that was stored at $25 \pm 2^{\circ} \mathrm{C}$ for 3 months. All measurements were carried out in triplicate and mean $\pm \mathrm{SD}$ was calculated.

\section{Preparation of Tadalafil-Loaded Limonene-Based Self-Nanoemulsifying Lyophilized Orodispersible Tablets (ODTs)}

The optimized tadalafil-loaded SNES was formulated into lyophilized ODT with the addition of different excipients. Various adsorbents were added, namely Syloid ${ }^{\mathbb{B}}$ XDP silica, microcrystalline cellulose (MCC), and lactose. Sodium starch glycolate (SSG) was used as superdisintegrant and glycerol as a cryoprotectant. Moreover, hydroxypropyl methylcellulose (HPMC), gelatin, and pregelatinized starch were utilized as binders and fillers.

Table 1 depicts the composition of the lyophilized ODT formulations. Mesoporous silica (Syloid ${ }^{\circledR}$ XDP) was utilized as a solid porous carrier to convert liquid ingredients into a freeflowing powder. These forms of silica provide a high mesoporous network, large surface area, high adsorption capacity, besides its desirable pore size and surface morphology. ${ }^{28}$ Lactose was used as a diluent to provide minimal disintegration time, sodium starch glycolate was exploited as superdisintegrant, glycerol as a cryoprotectant, and microcrystalline cellulose (Avicel) was used as filler, pregelatinized starch was added to enhance the bulk of the dosage form. Hydroxypropyl methylcellulose (HPMC) was used as a binder to maintain the integrity of the preparation, and gelatin - water-soluble polymer - served as a matrix-forming binder to uphold mechanical strength during manufacturing and patient handling. Initially, the specific weight of tadalafil-loaded SNES was mixed with $1 \% \mathrm{w} / \mathrm{v}$ gelatin $(10 \mathrm{~mL})$ until nanoemulsion is formed. According to formulation compositions, the excipients were added to the formed nanoemulsion slurry, and the mixture was sonicated on a bath sonicator for 10 minutes until homogenous dispersion is formed. This dispersion was poured into a tablet blister pack. ${ }^{20}$ The blisters were frozen at $-80^{\circ} \mathrm{C}$ for $24 \mathrm{~h}$, then freeze-dried using (LABCONCO, FreeZone 2.5 Liter Benchtop, US) Freeze Dry System at $-40^{\circ} \mathrm{C}$ and pressure of $6.5 \times 10^{-2}$ mbar. The lyophilized tablets were stored in closed desiccators over calcium chloride at room temperature until further testing.

\section{Evaluation of the Prepared Orodispersible Tablets}

\section{Physical Characteristics of the Prepared ODTs}

Weight variation test was performed by weighing 10 tablets individually (digital balance (ADB 100-4, Germany)), and the mean weight was calculated. Tadalafil content uniformity in ODT formulations was also assayed. Ten tablets were individually ground and dissolved in $50 \mathrm{~mL}$ methanol and sonicated for $10 \mathrm{~min}$. Samples were filtered and drug content was measured spectrophotometrically. ${ }^{20}$ Tablet thickness and diameter of 10 tablets were also measured using a micrometer (Vogel, Germany, DIN-863 micrometer). The average breaking force of 10 tablets (hardness) was assayed by a hardness tester (TBH 325 series, Erweka GmbH, Heusenstamm, Germany). A friability tester (Model FTV-2, Germany) was used to test tablets friability. Pre-weighed 10

Table I Composition of Lyophilized Orodispersible Tablets (ODTs) Incorporating the Tadalafil-Loaded Limonene-Based SelfNanoemulsifying System*

\begin{tabular}{|c|c|c|c|c|c|c|c|c|}
\hline $\begin{array}{l}\text { Excipients \% } \\
\text { w/v }\end{array}$ & $\begin{array}{l}\text { Syloid }^{\circledR} \text { XDP } \\
3050\end{array}$ & Lactose & $\begin{array}{l}\text { Avicel }^{\circledR} \text { PH- } \\
\text { I0I }\end{array}$ & $\begin{array}{l}\text { Na Starch } \\
\text { Glycolate }\end{array}$ & $\begin{array}{l}\text { HPMC } \\
\text { k4 }\end{array}$ & Gelatin & $\begin{array}{l}\text { Pregelatinized } \\
\text { Starch }\end{array}$ & Glycerol \\
\hline $\mathrm{FI}$ & 4 & 4 & $x$ & $x$ & 2 & 2 & I & I \\
\hline F2 & 2 & 4 & $x$ & $x$ & 0.5 & 2 & I & I \\
\hline F3 & 2 & 2 & $x$ & 2 & 0.5 & 2 & I & I \\
\hline F4 & $x$ & 3 & $x$ & 3 & 0.5 & 2 & I & I \\
\hline F5 & 2 & $x$ & 2 & 2 & 0.5 & 2 & I & I \\
\hline F6 & $x$ & $x$ & 3 & 3 & 0.5 & 2 & I & I \\
\hline
\end{tabular}

Note: *Each tablet contains $33 \mathrm{mg}$ tadalafil. 
tablets were placed in the friabilator at $25 \mathrm{rpm}$ for $4 \mathrm{~min}$ according to USP $37-\mathrm{NF} 32 .^{29}$ Tablets were reweighed and the percentage friability was calculated according to equation 1 (no more than $1 \%$ loss from initial weight to be accepted).

$$
\% \text { Friability }=\frac{\text { Loss in weight }}{\text { Initial weight }} \times 100
$$

\section{Disintegration Time, Wetting Time, and Water Absorption Ratio}

Six tablets were used to determine the disintegration time employing USP disintegration tester (ZT 220 series, Erweka $\mathrm{GmbH}$, Germany) in $900 \mathrm{~mL}$ deionized water at $37 \pm 2^{\circ} \mathrm{C}$ at 30 agitation/min. For the wetting time test, a twice folded tissue paper in a small petri dish containing $6 \mathrm{~mL}$ aqueous methylene blue (water-soluble dye) solution was used. ${ }^{30}$ One tablet from each formulation was weighed $\left(\mathrm{W}_{\mathrm{a}}\right)$ and placed in the petri dish and the time required for the dye to reach the upper surface of the tablet was recorded as the wetting time. The tablet was weighed again $\left(\mathrm{W}_{\mathrm{b}}\right)$ and the water absorption ratio $(\mathrm{R})$ was computed $^{31}$ according to the following equation;

$$
\mathrm{R}=\frac{\mathrm{W}_{\mathrm{b}}-\mathrm{W}_{\mathrm{a}}}{\mathrm{Wa}} \times 100
$$

\section{In-vitro Dissolution Study}

The in-vitro dissolution rate of tadalafil from the passed formulations was conducted to compare its pattern of release from the prepared ODTs and its physical mixture; each contains an equal amount of tadalafil. The study was carried out in $500 \mathrm{~mL}(0.1 \mathrm{~N} \mathrm{HCl}, \mathrm{pH} 1.2,2 \% \mathrm{w} / \mathrm{v}$ Tween ${ }^{\circledR} 80$ ) dissolution media, at $50 \mathrm{rpm}$ and $37 \pm 2{ }^{\circ} \mathrm{C}$ using United States Pharmacopoeia (USP) apparatus II paddle method. ${ }^{32}$ Samples were periodically withdrawn and replaced with the same volume of fresh dissolution medium. Samples were analyzed for its tadalafil content spectrophotometrically at $\chi \max 291 \mathrm{~nm}$.

\section{In-vivo Assessment Animals}

The comparative study of the gastroprotective effect of the prepared formulations was carried on Wistar Albino male rats weighing 200 to $250 \mathrm{~g}$. The animals were procured by the animal house of Beirut Arab University, Beirut, Lebanon. The rats were housed under standard laboratory conditions, kept under diurnal light, and had free access to water and standard chow diet before the experiment. ${ }^{33}$ The procedures were performed according to the regulations and guidelines stipulated by the institutional animal care and use guideline (IACUG) at Beirut Arab University, authenticated by the ministry of public health (2020A-055-P-R-0379).

\section{Induction of Gastric Ulcer}

Twenty-four hours before the procedure, each rat was kept in an individual cage and was deprived of food, only water was provided. On the day of the experiment, rats were grouped into five groups of five rats each. All the groups received the treatments orally. The first group was considered the negative control group which received orally normal saline $(0.9 \% \mathrm{NaCl})$ at a dose of $8 \mathrm{~mL} / \mathrm{kg}^{33}$ The second group, the positive control, received omeprazole (Gastrimut ${ }^{\circledR}$ ) at an oral dose of $20 \mathrm{mg} / \mathrm{kg} .{ }^{34}$ The third group was pretreated orally with $10 \mathrm{mg} / \mathrm{kg}$ tadalafil aqueous suspension. The fourth group received tadalafilloaded limonene-based SNES ODT dispersed in normal saline to obtain an equivalent dose, ${ }^{35}$ while the fifth group received an equal volume of unloaded limonene-based SNES ODT also dispersed in normal saline. One hour later, the ulcer was induced by an oral administration of $1 \mathrm{~mL}$ of $80 \%$ ethanol. Oral administration procedures were performed with the aid of oral gavage. All rats were sacrificed after $1 \mathrm{~h}$ by overdosing with thiopental. Stomachs were removed, cut along the greater curvature, and rinsed with saline. ${ }^{36}$

\section{Evaluation of Gastric Lesion}

After scarification, stomachs were removed and pinned on a dissecting tray and photographed. The degree of ulceration was assessed using the ulcer scoring system represented by Abou Zeit-Har. ${ }^{37}$ The ulcer score was determined by the sum of the total ulcer score for each stomach. The ulcer area $\left(\mathrm{mm}^{2}\right)$ and total stomach area $\left(\mathrm{mm}^{2}\right)$ were determined by Image $J$ software version 1.52a (National Institute of Health, USA). The ulcer index (UI) and protection percentage were determined based on the following formula: ${ }^{38}$

$$
\mathrm{UI}=\left(\frac{\text { ulcer area }}{\text { total area }}\right) \times 100
$$

$\begin{aligned} \operatorname{Protection}(\%)= & \left(\frac{\mathrm{UI} \text { control }- \text { UI of pre }- \text { treated group }}{\text { UI of control }}\right) \\ & \times 100\end{aligned}$ 


\section{Histopathological Assessment}

For histopathological evaluation, the isolated stomachs were fixed in buffered neutral formalin solution, trimmed, and dehydrated. The sample portion of the stomachs was embedded in paraffin wax and sectioned into 3-5 $\mu \mathrm{m}$ using a rotary microtome (cut 5040, Micrototec, Walldorf). Slides were stained with hematoxylin and eosin and examined under a light microscope. ${ }^{39}$

\section{Stability of the Tadalafil ODTs}

The optimum ODT formulation was assayed for its stability according to the International Conference on Harmonization ( $\mathrm{ICH})$ guidelines. The tablets were stored in sealed vials and at $40 \pm 2{ }^{\circ} \mathrm{C}$ and $75 \pm 5 \% \mathrm{RH}$ for 3 months. At a one-month time interval, the tablets were inspected for their physical characteristics, hardness, \% friability, drug content, and disintegration time. $^{40}$

\section{Statistical Analysis}

In-vitro studies were performed in triplicate while in-vivo experiments were carried on a group of five animals. Results were analyzed using Statistical Package for the Social Science version 20 (IBM Corporation, Armonk, NY, USA). Continuous data were expressed as mean \pm SD. $t$-test or One-way analysis of variance (ANOVA) followed by post hoc Tukey's test was used when appropriate. The difference was considered significant at a $p$-value of less than or equal to 0.05 .

\section{Results and Discussion Solubility Study}

The solubility of tadalafil in the optimized formula was performed to determine the amount of tadalafil that could be solubilized within the formulation. Tadalafil solubility in water was $0.0053 \mathrm{mg} / \mathrm{mL}$, confirming its poor solubility following the previously reported data. ${ }^{41}$ The solubility of tadalafil in limonene-based SNES was $5.4265 \mathrm{mg} / \mathrm{mL}$, indicating an enhancement in tadalafil solubility by 1000 folds, this represents a promising carrier system that can be used for efficient oral delivery of tadalafil. This improvement in the drug solubility is due to the presence of surfactant and cosurfactant and the small droplet size of the preparation. A similar phenomenon was observed for the solubility of celecoxib in nanoemulsion which showed a significant enhancement compared with other formulations. The enhancement in celecoxib solubility was
38,040-, 24,036-, and 7185-folds in nanoemulsion, solidlipid nanoparticles, and solid dispersion, respectively, as compared to water. ${ }^{42}$

\section{Physicochemical Characteristics of Tadalafil-Loaded Limonene-Based Nanoemulsion}

In the current study, tadalafil-loaded formulation droplet size was $104 \pm 1.53 \mathrm{~nm}$ slightly smaller than that of the unloaded formula $(113 \pm 1.18 \mathrm{~nm})(p<0.05)$, and this variation in droplet size is justified by the penetration of the hydrophobic tadalafil molecules and limonene oil into the hydrophobic region of Tween ${ }^{\circledR} 80$ that changed film flexibility, surface bend, and eventually droplet size. ${ }^{43}$ The polydispersity index (PDI) is another parameter to be evaluated. When its value is closer to zero, indicates the homogeneity of the preparation and uniformity of droplet size. ${ }^{44}$ PDI value of tadalafil-loaded limonene-based SNES and that of the unloaded were the same. This implies that the loading of the drug did not affect the formulation homogeneity, uniformity, and distribution of the droplets within the nanosystem. Similar results were represented by Ali and Hussein, for candesartan-loaded nanoemulsion, as PDI values were less than $0.5 .{ }^{43}$ Zeta potential value of tadalafil-loaded limonene-based SNES was $-13.5 \pm 1.9 \mathrm{mV}$ less than that of unloaded formulation, yet it is still negatively charged providing stability to the nanoemulsion system. This zeta potential value matches that reported for hydrochlorothiazide nanoemulsion which was -15.4 $\pm 0.1 \mathrm{mV}^{25}$ After 3 months of storage at room temperature, the particle size of the loaded preparation did not change (107 \pm 0.03$)$, PDI remained less than $0.5(0.2$ $\pm 0.003)$ and the same zeta potential value $(-14.53 \pm 0.04)$ was maintained. The physiochemical characteristics of the tadalafil-loaded limonene-based self-nanoemulsifying system showed a non-significant difference $(p<0.05)$.

\section{Physical Stability of Tadalafil SNES}

Different thermodynamic stability tests were performed to evaluate the stability of the loaded formula. These tests included centrifugation and cycles of freeze-thawing. The results are listed in Table 2. Both drug-loaded and unloaded formulations showed maximum stability with neither phase separation nor precipitation indicating firmness against drastic conditions, namely temperature and centrifuge force. Our results are in agreement with that represented by Nasr et al where the prepared olmesartan- 
Table 2 Thermodynamic Stability and Self-Emulsification Time of Tadalafil-Loaded and Unloaded Limonene-Based Self-Emulsifying Delivery System

\begin{tabular}{|l|l|l|l|l|l|}
\hline Formula & $\begin{array}{l}\text { Percentage } \\
\text { Transmittance* } \\
(\%)\end{array}$ & $\begin{array}{l}\text { Cloud } \\
\text { Point* } \\
(\mathbf{0})\end{array}$ & $\begin{array}{l}\text { Self-Emulsification } \\
\text { Time* } \\
(\mathbf{s})\end{array}$ & $\begin{array}{l}\text { Centrifugation } \\
\text { Test }\end{array}$ & $\begin{array}{l}\text { Freeze-Thawing } \\
\text { Test }\end{array}$ \\
\hline $\begin{array}{l}\text { Tadalafil-loaded SNES } \\
\text { Limonene-based SNES }\end{array}$ & $\begin{array}{l}94.77 \pm 1.05 \\
92.57 \pm 0.98\end{array}$ & $\begin{array}{l}73 \pm 1.52 \\
72 \pm 1.73\end{array}$ & $\begin{array}{l}33.66 \pm 1.52 \\
37 \pm 2.52\end{array}$ & $\begin{array}{l}\text { Passed }^{*} \\
\text { Passed }^{*}\end{array}$ & $\begin{array}{l}\text { Passed }^{*} \\
\text { Passed }^{*}\end{array}$ \\
\hline
\end{tabular}

Notes: *Results are expressed as mean \pm SD $(n=3)$; 'Self-nanoemulsifying system was stable and no changes in its physicochemical characteristics were observed.

loaded SNES was stable and showed no signs of precipitation, cloudiness, or phase separation after centrifugation and six freeze-thaw cycles. ${ }^{45}$ The self-emulsification time of tadalafil-loaded limonene-based SNES was 33.66 $\pm 1.52 \mathrm{~s}$ less than that of the unloaded limonene-based $(37.00 \pm 2.52 \mathrm{~s})$. This indicates the efficiency of the spontaneous emulsification of the formula, as it is supposed to disperse directly upon contact with aqueous medium without any external aid but mild agitation. ${ }^{25}$ The ease of emulsification of the SNES is related to the effortless penetration of water into the colloidal phase on the surface of the droplets. ${ }^{46}$ The loaded SNES showed an identical stability profile over $24 \mathrm{~h}$ as that of the unloaded limonene-based preparation, without any phase separation or precipitation, due to the neutral effect of the drug and its high solubility within the system. This stability following dilution with different dissolution media is an essential criterion especially for the oral preparations as these media mimic GIT secretions, similar to dutasteride SNES. ${ }^{47}$ The percentage transmittance of the prepared tadalafil-loaded limonene-based SNES was $94.77 \pm 1.05$ (Table 2) more than that of the unloaded limonene-based nanoemulsion 92.57 $\pm 0.98 \quad(p<0.05)$. According to a previous study, there is a strong correlation between percentage transmittance and droplet size ${ }^{48}$ and this explains our results where the droplet size of tadalafil-loaded SNES is less than that of the unloaded formula, the percentage transmittance of the first increased. As shown in Table 2, tadalafil-loaded limonene-based SNES and the unloaded formula had a cloud point temperature above $70^{\circ} \mathrm{C}$ and showed no signs of instability. These results are similar to those of Avachat et al where the cloud point of the SNES of ellagic acidphospholipid complex was $74^{\circ} \mathrm{C} .{ }^{49}$

\section{Lyophilized Orodispersible Tablets (ODT) Tadalafil-Loaded Limonene-Based Self-Nanoemulsifying System: Preparation and Assessment}

To assess and compare the gastroprotective effect of tadalafil alone and in combination with natural oil component against induced gastric ulcers, tadalafil-loaded limonene-based SNES was incorporated into lyophilized ODTs. The choice of excipients is essential for the development of a tablet formulation and also for the quality control of dosage forms. Several formulations were prepared using different ingredients in six series incorporated the optimized tadalafil limonene-based liquid SNES (Table 1). Values of the physical parameters accessed of the six different tadalafil ODTs are mentioned in Table 3. The weight variation of all formulations was non-significantly different $(p>0.05)$ and met the pharmacopeia requirements and the results ranged between $113.25 \pm 6.31 \mathrm{mg}$ to $167.87 \pm 3.34 \mathrm{mg}$, indicating proper formulation. Tablets obtained in the six formulations had a uniform weight within the acceptable variation as per USP specifications, ie, $( \pm 10 \%)$ (United States

Table 3 Physical Characteristics of the Lyophilized Tadalafil ODTs

\begin{tabular}{|c|c|c|c|c|c|}
\hline ODT Formulation & Average Weight (mg)* & Uniformity Content & Thickness $(\mathrm{mm})^{*}$ & Hardness $\left(\mathrm{kg} / \mathrm{cm}^{2}\right)^{*}$ & Friability (\%)* \\
\hline $\mathrm{FI}$ & $151.73 \pm 4.95$ & $98.64 \pm 0.53$ & $2.57 \pm 0.12$ & $4.15 \pm 0.31$ & $0.23 \pm 0.36$ \\
\hline F2 & || $3.82 \pm 6.3 \mid$ & $98.38 \pm 0.16$ & $2.40 \pm 0.09$ & $3.38 \pm 0.44$ & $0.44 \pm 0.82$ \\
\hline F3 & $133.25 \pm 2.39$ & $99.57 \pm 0.21$ & $2.36 \pm 0.10$ & $3.02 \pm 0.38$ & $0.56 \pm 0.09$ \\
\hline F4 & $167.87 \pm 3.34$ & $98.16 \pm 0.65$ & $2.48 \pm 0.04$ & $3.78 \pm 0.26$ & $0.27 \pm 0.95$ \\
\hline F5 & $|57.35 \pm 3.3|$ & $98.58 \pm 0.59$ & $2.4 I \pm 0.02$ & $3.36 \pm 0.21$ & $0.42 \pm 0.15$ \\
\hline F6 & $138.06 \pm 1.11$ & $99.14 \pm 0.34$ & $2.31 \pm 0.03$ & $3.1 I \pm 0.24$ & $0.60 \pm 0.01$ \\
\hline
\end{tabular}

Note: *All values are expressed as mean \pm SD. 
Pharmacopeial Convention, 2014) ${ }^{29}$ The drug content in all formulations was more than $95 \%(\mathrm{p}>0.05)$ as presented in Table 3, which is within the pharmacopeia limits of 90 to $110 \%$ (Al-Amodi et al, 2020). The thickness of the six prepared tadalafil ODTs ranged from $2.31 \mathrm{~mm}$ to $2.57 \mathrm{~mm}$. The presence of HPMC as a matrix-forming material in all the formulation maintained the integrity of the preparation due to the long chains of this polymer that upon drying extend and form a solid cross-linking network that minimizes the tablet porosity and increases its hardness. ${ }^{50}$ It was found that all the formulations had hardness in the range of 3.02 to $4.15 \mathrm{~kg} / \mathrm{cm}^{2}$ and friability between 0.23 and $0.60 \%$ (less than 1\%) indicating satisfactory mechanical strength. Liew and Peh investigated the effect of three polymers (hydroxypropylmethylcellulose, carbopol 934P, and Eudragit ${ }^{\circledR} \mathrm{EPO}$ ) on ODTs hardness and found that HPMC provided a stronger effect on tablet hardness compared to Carbopol 934P at the same concentration level. ${ }^{51}$ Additionally, the presence of freeze-dried frozen gelatin in the formulations imprisoned frozen water to sublimate, allowing the presence of only a more stable and widespread 3D network forming crosslinks and interchain hydrogen bonds, hence supporting tablet hardness. ${ }^{52,53}$

Disintegration time, wetting time, and water absorption ratio are validated in Table 4 . The acceptable disintegration time according to the USP standard $(<1 \mathrm{~min})$, while the actual disintegration a patient can experience is between $5 \mathrm{~s}$ and 30 $\mathrm{s},{ }^{30}$ and thus all the formulas except F1 were accepted. Formulas F3 and F6 showed the shortest disintegration time and wetting time $(33 \pm 1 \mathrm{~s}, 21.33 \pm 4.5 \mathrm{~s}$ for F3 and $28 \pm 2.64 \mathrm{~s}$, $23.67 \pm 1 \mathrm{~s}$ for F6, respectively). As for the water absorption ratio, both formulas presented the highest ratio (419.30 and 572.82, respectively). According to Hirani et al, a shorter wetting time suggests a faster disintegration of the tablet. ${ }^{54}$ Additionally, a good correlation between wetting time and

Table 4 Disintegration Time, Wetting Time, and Water Absorption Ratio of the Lyophilized Tadalafil ODTs

\begin{tabular}{|l|l|l|l|}
\hline Formulation & $\begin{array}{l}\text { Disintegrating } \\
\text { Time (s)* }\end{array}$ & $\begin{array}{l}\text { Wetting } \\
\text { Time (s)* }\end{array}$ & $\begin{array}{l}\text { Water } \\
\text { Absorption } \\
\text { Ratio }\end{array}$ \\
\hline FI & $62.00 \pm 3.5 I$ & $63.00 \pm 3.60$ & 201.39 \\
F2 & $41.67 \pm 7.57$ & $40.00 \pm 2.30$ & 166.20 \\
F3 & $33.00 \pm 1.00$ & $21.33 \pm 4.50$ & 419.30 \\
F4 & $47.88 \pm 3.51$ & $57.00 \pm 3.00$ & 129.29 \\
F5 & $41.55 \pm 3.78$ & $46.33 \pm 8.62$ & 206.14 \\
F6 & $28.00 \pm 2.64$ & $23.67 \pm 1.00$ & 572.82 \\
\hline
\end{tabular}

Note: *Values are expressed as mean $\pm S D$. disintegration time was detected in all formulations $\left(\mathrm{R}^{2}=\right.$ 0.93). Formulations F3 and F6 exhibited high hardness and low $\%$ friability (Table 3 ) which affected disintegration and wetting time. Wetting time and disintegrating time increased as a function of hardness $\left(\mathrm{R}^{2}=0.95\right.$ and 0.98 , respectively), and decreased as a function of friability (negative correlation coefficient -0.94 and -0.98 , respectively). Sodium starch glycolate (SSG) is a porous structure that forms tablets with rapid water uptake through swelling mechanism due to amylopectin component in its structure. The presence of SSG as superdisintegrant is responsible for the high water absorption ratio in F3 and F6. A similar outcome was established by Rojas et al who investigated four types of disintegrants, namely croscarmellose sodium, crospovidone, sodium starch glycolate, and microcrystalline cellulose, and reported that water sorption ratio and swelling values of SSG followed by croscarmellose sodium were the highest, whereas crospovidone and MCC were the least swelling disintegrants. ${ }^{55}$ The amount of SSG in F6 was higher than that in F3, which weakened the breaking strength, caused a shorter disintegration time and the highest water absorption ratio, due to lower compression force and the porous structure of SSG facilitated water uptake into the table. Likewise, the presence of Avicel ${ }^{\circledR}$ in F6 decreased the disintegration time to be less than that in F3 $(p=0.01)$. Although microcrystalline cellulose is not generally used as superdisintegrant, yet when it is used below $10 \%$, it provides good disintegration properties. MCC acts via a wicking mechanism that upon water exposure, these pores break H-bonds between adjacent microcrystalline bundles, allowing water to enter into the tablets thus further reduction in disintegration time occurs. The combination of MCC and SSG in F6 created a synergistic effect that decreased disintegration time and elevated water absorption ratio. Similar results were reported by Desai et al for the rapid disintegrating ascorbic acid tablets, where MCC provided the capillary network for water intake into the tablets and enhanced the swelling of SSG. ${ }^{56}$ Therefore, and based on the insignificant difference of the previously mentioned tests between $\mathrm{F} 3$ and F6 ( $>>0.05$ ), both formulations were subjected to the in-vitro release study.

\section{In-vitro Dissolution Studies}

The comparison of tadalafil dissolution from F3, F6, and tadalafil physical mixture is demonstrated in Figure 1. Faster initial release $(p<0.05)(68.50 \pm 0.03 \%)$ within $10 \mathrm{~min}$ of tadalafil from F6 than from F3 $(54.55 \pm 0.002 \%)$ was observed compared with the physical mixture (5.2\%). More than $80 \%$ of tadalafil was released after $30 \mathrm{~min}$ from 


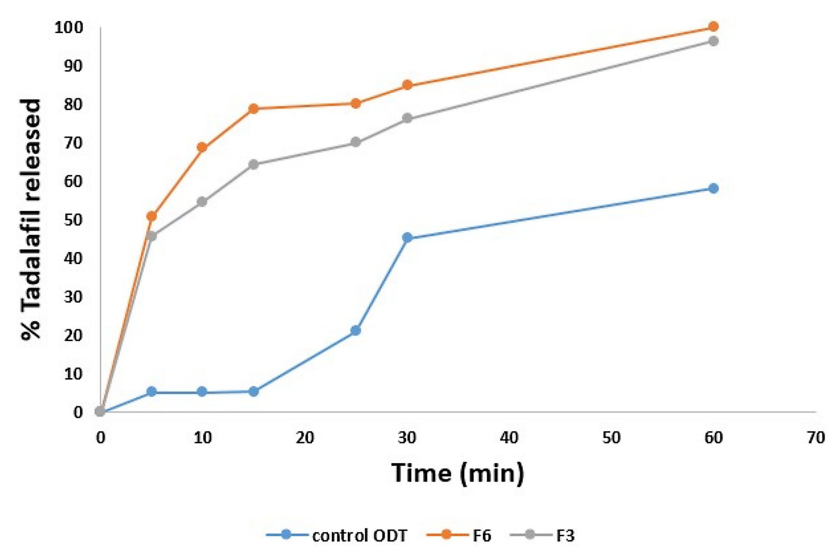

Figure I Dissolution profiles of F3 and F6 tadalafil orodispersible tablets and physical mixture (control) in $0.1 \mathrm{~N} \mathrm{HCl}$ containing $2 \%$ Tween ${ }^{\circledR} 80$ stirred at $50 \mathrm{rpm}$ maintained at $37 \pm 0.5^{\circ} \mathrm{C}$.

F6 compared to $75 \%$ from $\mathrm{F} 3$ and $45 \%$ from the physical mixture $(p<0.05)$. Almost complete dissolution was observed with F6 and F3 after $1 \mathrm{~h}$. To compare the release profile of tadalafil from F6, F3, and its physical mixture, the mean dissolution rate (MDR) was calculated. The mean dissolution rate of tadalafil-loaded F6 (1.02) and of F3 (0.98) was significantly greater than that of tadalafil physical mixture $(0.12)$ by 8 -folds $(p<0.05)$. Model-independent parameters such as mean dissolution rate help to predict an overview of the dissolution rate of a sample during the dissolution process. The 8 -folds increase in the mean dissolution rate agrees with those of Mehanna et al where the release rates of tadalafil from solid dispersion compared with the pure drug were higher by 10 -folds ${ }^{57}$ and prove that SNES preparation provided major enhancements in dissolution rate, due to solubility enhancement, incorporation of surfactant and co-surfactant and the small diameter of the oil droplets. As a consequence of the statistical difference in the initial release rate between the two formulations, F6 was nominated for further studies.

The kinetic study showed that the best fit was achieved with Korsemeyer-Peppas which indicated that the drug release mechanism from F6 was the one of diffusion. In this study, the diffusion behavior of tadalafil was related to Fickian diffusion $(n=0.17)$. Fickian diffusional release occurs by the usual molecular diffusion of the drug due to a chemical potential gradient. ${ }^{58}$

\section{In-vivo Gastric Protection of ODTs}

After scarification, the stomachs were removed, cut along the great curvature rinsed with normal saline then pinned on a dissecting plate to be visually examined. An ulcer score was calculated for each stomach using the Abou Zeit-Har scale. ${ }^{37}$ Afterward, the stomachs were photographed by the camera, and the ulcer area was determined. In the negative control group, severe large and very large ulcers with hemorrhagic erosions were observed as shown in Figure 2A with a score of $79 \pm 27.40$, an ulcer area of $65.57 \pm 31.47 \mathrm{~mm}^{2}$, and an ulcer index of $14.41 \pm 4.10$ (Table 5). The ulcer has also been linked to increasing lipid peroxidation that generates free radicals that attack the gastric cells causing erosive lesions and ulceration. ${ }^{59}$ Additionally, ethanol can solubilize the gastric mucus barrier allowing the penetration of aggressive factors like $\mathrm{HCl}$ and pepsin rapidly leading to mucosal damage. ${ }^{60}$ The obtained results are equivalent to the ones reported in the Guzman-Gomez et al study where rats in the control group suffered from severe gastric lesions in the mucosa layer characterized by thick linear hemorrhage with an ulcer index of $13.73 \pm 1.5 .^{61}$

Since the gastric ulcers develop as a consequence of an imbalance between the aggressive factors in the gastric system, including gastric acids or pepsin, and the protective factors, such as mucus secretion, prostaglandins, sulfhydryl compounds, nitric oxide, and antioxidants. Thus, the typically recommended regimen for ulcer management is the use of acid suppressants including proton pump inhibitors, exemplified by omeprazole. Rats pre-treated with omeprazole at a dose of $20 \mathrm{mg} / \mathrm{kg}$ showed small ulcers of 1-2 $\mathrm{mm}$ long with some hemorrhagic erosion (Figure 2B). Abou Zeit-Har score of the stomachs was $20.20 \pm 14.62$, while ulcer area and ulcer index values were $16.90 \pm 5.41 \mathrm{~mm}^{2}$ and $3.70 \pm 0.91$, respectively (Table 5 ), implicating that omeprazole protected the stomachs by $74.33 \pm 6.31 \%$ as illustrated in Figure 3 with a statistically significant difference compared to the negative control group. Omeprazole inhibits the secretion of gastric acid by irreversible blocking of the hydrogen/potassium adenosine triphosphate enzyme system of the gastric cells. ${ }^{62}$

Prior treatment with tadalafil suspension revealed few medium to large ulcers, but significantly less than those observed in the negative controlled group (Figure 2C). This pretreatment led to $59.64 \pm 11.70 \%$ gastroprotection against ethanol ulcer induction, which was significantly lower than omeprazole pre-treated group although the ulcer area, as well as the ulcer index, were significantly lower than the negative control with values of $21.60 \pm 9.33$ and $5.81 \pm 1.67$ versus $65.57 \pm 31.47$ and $14.41 \pm 4.10$ (Figure 3, Table 5). These results may be explained based on the nature of nitric oxide (NO) as a protective factor to the gastric mucosa; 

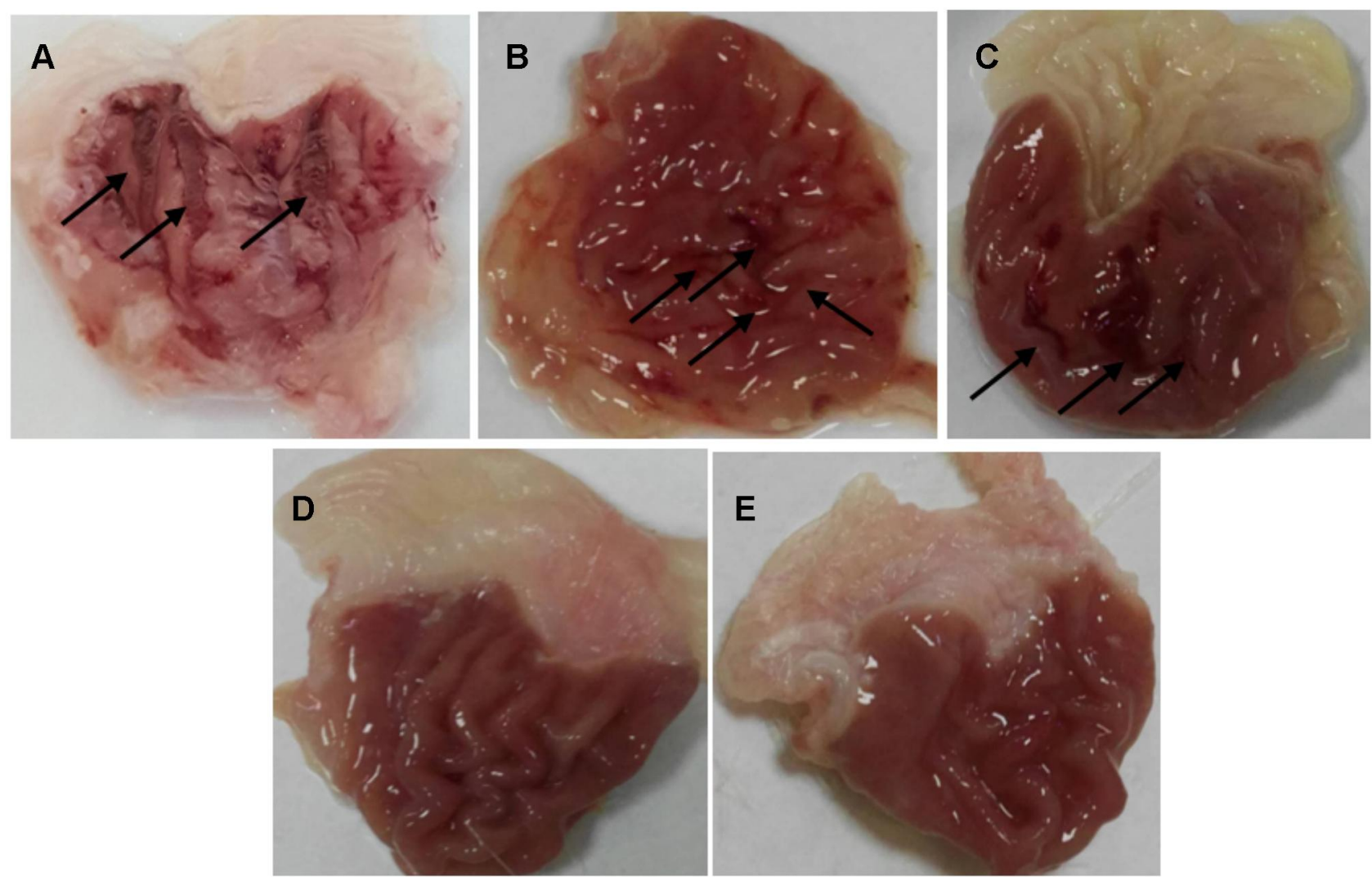

Figure 2 The effect of different pre-treatment modalities on the macroscopical appearance of the gastric mucosa after ethanol oral administration. (A) saline (negative control), (B) omeprazole (positive control), (C) tadalafil aqueous suspension, (D) tadalafil-loaded limonene-based self-nanoemulsifying lyophilized orodispersible tablet, (E) limonene-based self-nanoemulsifying lyophilized orodispersible tablet. The arrows indicate ulcers and hemorrhagic erosions.

thus, any agent that promotes nitric oxide action, including phosphodiesterase inhibitors, may exhibit a gastroprotective effect. ${ }^{63}$ To study the influence of tadalafil incorporation into self-nanoemulsifying-based lyophilized ODT, formula F6 was administered to rats $1 \mathrm{~h}$ before ethanol oral

Table 5 The Effect of Different Treatment Modalities on Induced Gastric Ulcer in Rats

\begin{tabular}{|l|l|l|l|}
\hline Treated Models & $\begin{array}{l}\text { Abou Zeit- } \\
\text { Har Score }\end{array}$ & $\begin{array}{l}\text { Ulcer Area } \\
\left(\mathbf{m m}^{\mathbf{2}}\right)\end{array}$ & $\begin{array}{l}\text { Ulcer } \\
\text { Index }\end{array}$ \\
\hline $\begin{array}{l}\text { Saline (negative control) } \\
\text { Omeprazole } \\
\text { (positive control) }\end{array}$ & $\begin{array}{l}79.0 \pm 27.40 \\
20.2 \pm 14.62^{*}\end{array}$ & $\begin{array}{l}65.57 \pm 31.47 \\
16.90 \pm 5.41^{*}\end{array}$ & $\begin{array}{l}\mid 4.41 \pm 4.10 \\
\text { Tadalafil aqueous } \\
\text { suspension } \\
\text { Tadalafil-loaded } \\
\text { limonene-based SNES } \\
\text { ODTs }\end{array}$ \\
$\begin{array}{l}\text { Limonene-based SNES } \\
\text { ODTs }\end{array}$ & $31.2 \pm 9.70^{*}$ & $21.60 \pm 9.33^{*}$ & $5.81 \pm 1.69 *$ \\
\hline
\end{tabular}

Notes: $\mathrm{n}=5$ (mean $\pm \mathrm{sd}$ ); *Denotes significant difference from saline-treated group (negative control) $(p<0.05)$; "Denotes significant difference from omeprazole treated group (positive control) $(p<0.05)$.

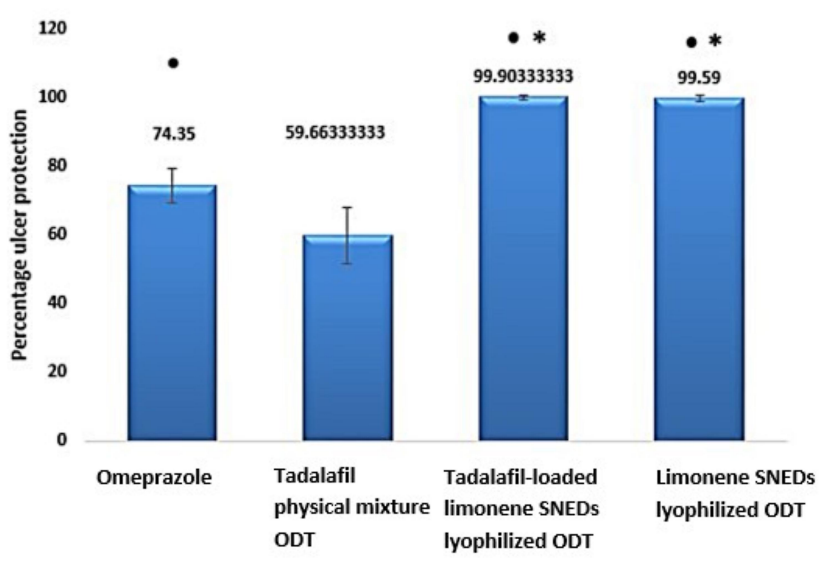

Figure 3 Percentage of ulcer protection in different pre-treatment groups on an ethanol-induced ulcer in rats $(n=10)$. *Denotes significant difference compared to the positive control (omeprazole-treated group) and ${ }^{\bullet}$ Denotes significant difference compared to tadalafil aqueous suspension.

administration. The results showed that the prepared formulation exhibited an almost normal gross mucosal structure (Figure 2D) with $99.90 \pm 0.22 \%$ protection against ulcer induction, which was significantly higher than the omeprazole pre-treated group. Nevertheless, unloaded limonene- 
based SNES lyophilized ODT, presented a normal gross mucosal structure (Figure 2E) typically as the loaded formulation with a statistically non-significant different gastroprotection of $99.59 \pm 11.70 \%$ (Figure 3) with intact duodenum. Abou Zeit-Har score, ulcer area, and ulcer index of the tadalafil-loaded limonene-based SNES ODT treated group was non-significantly lower than the limonenebased SNES treated group with values of $0.2 \pm 0.45,0.05$ \pm 0.12 , and $0.01 \pm 0.03$, versus $1.6 \pm 2.07,0.24 \pm 0.25$, and 0.59 \pm 0.06 , respectively (Table 5). This implies that limonene had demonstrated a gastroprotective effect that acted synergistically with tadalafil in the form of SNES ODT for further enhancement in its efficacy of gastric ulcer prevention.

\section{Histological Evaluation}

For further investigation of the gastric mucosa lesions, histological observation stained by H\&E was accomplished and presented in Figure 4. The microscopical qualitative examination of the stomach histology of the saline-treated group (negative control) revealed necrosis with a disrupted mucosal layer (Figure 4A). The observed mucosal damage is due to the inability of saline to protect the gastric mucosa from the necrotic effect of ethanol which due to the decrease of the defensive factors, namely bicarbonate, mucus, and blood flow, in addition to accelerating oxidative stress by generating free radicals and peroxidation of lipid in the gastric mucosa. ${ }^{64}$ Moreover, congestion along with inflammation appeared in the omeprazole pre-treated group manifested by the infiltration of fibroblasts and leucocytes (Figure 4B). These results are comparable to those of Cheong et al where the negative control group showed extensive damage of the gastric mucosa, while that treated with omeprazole was subjected to edema and leukocyte infiltration. ${ }^{34}$ Interestingly, the gastric tissue of the limonene-based ODTs treated group demonstrated almost normal mucosa with minor inflammation and submucosal hemorrhage (Figure 4E). This protection is attributed to the marked gastroprotective activity of limonene against ulcer, which is mediated by inhibition of cytokines, increase the mucus level as well as vasoactive intestinal peptides, decrease ulcer severity, and preserve gastric mucosal integrity. ${ }^{65}$ Mild necrosis with submucosal hemorrhage was observed in the tadalafil suspension-treated group, while a normal intact epithelial layer was noticed with the tadalafil-loaded SNES ODT treated group (Figure 4C and D). The gastroprotective activity of tadalafil was mediated by nitric oxide, which is a potent vasodilator that increases blood flow to mucosal tissue, preventing its damage. Although tadalafil demonstrated a dose-dependent ulcer reducing activity against indomethacin-induced ulcer compared with cimetidine, ${ }^{16}$ the loading of tadalafil into limonene-based SNES ODTs
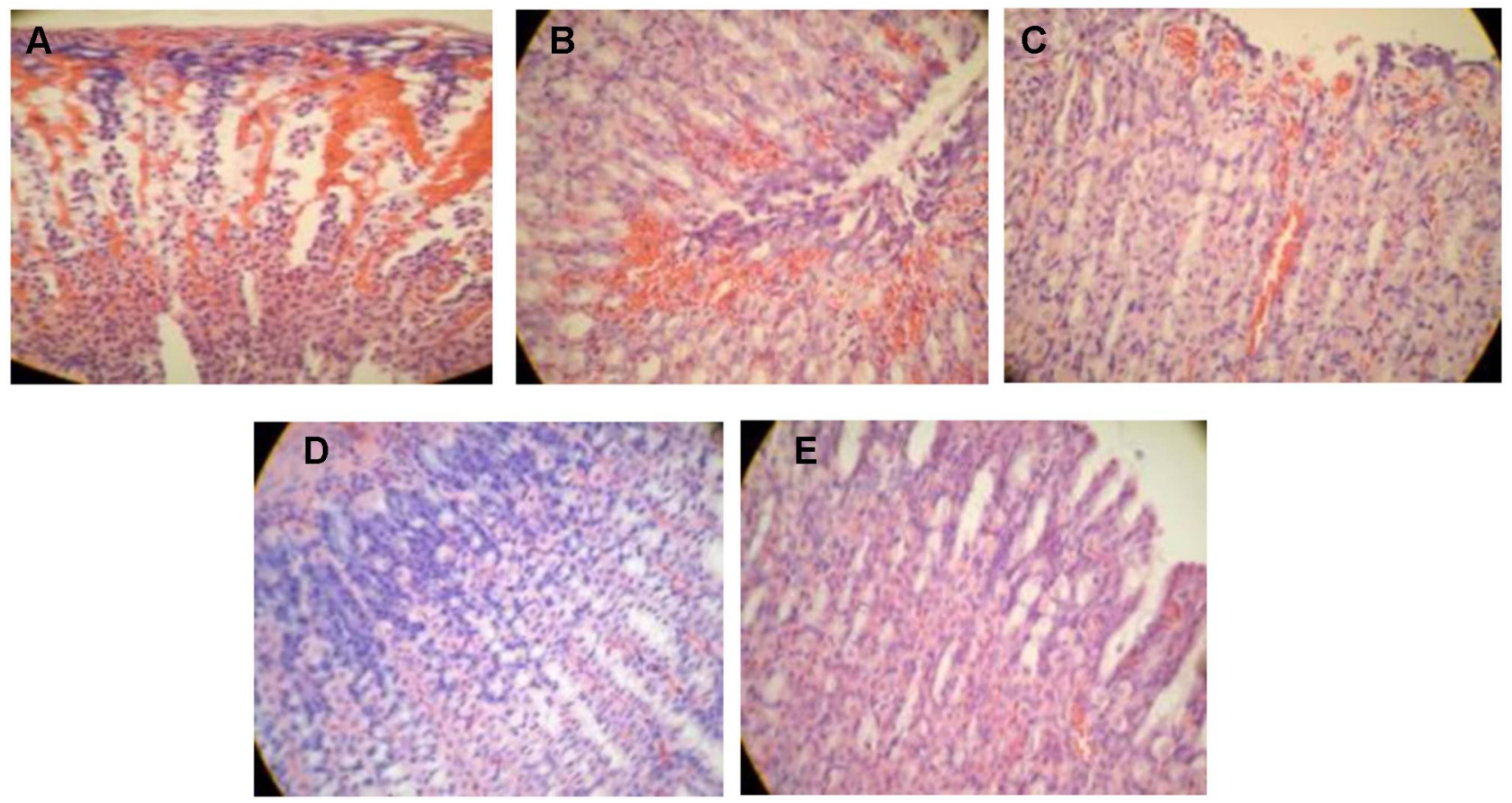

Figure 4 Histopathological features of rat stomachs pre-treated with (A) saline (negative control), (B) omeprazole (positive control), (C) tadalafil aqueous suspension, (D) tadalafil-loaded limonene-based self-nanoemulsifying ODT, (E) limonene-based self-nanoemulsifying ODT, after the administration of I mL $80 \%$ ethanol. 
Table 6 The Stability of the Optimized Lyophilized Tadalafil ODT After Three Months of Storage*

\begin{tabular}{|c|c|c|c|}
\hline & $\begin{array}{l}\text { Hardness } \\
\left(\mathrm{kg} / \mathrm{cm}^{2}\right)\end{array}$ & $\begin{array}{l}\text { Friability } \\
\text { (\%) }\end{array}$ & $\begin{array}{l}\text { Content } \\
\text { Uniformity }\end{array}$ \\
\hline Freshly prepared & $3.11 \pm 0.24$ & $0.60 \pm 0.01$ & $99.14 \pm 0.34$ \\
\hline After three months & $3.05 \pm 0.17$ & $0.53 \pm 0.11$ & $98.21 \pm 0.02$ \\
\hline
\end{tabular}

Note: *Results are expressed as mean $\pm S D(n=3)$.

improved the solubility and enhanced its efficacy in protecting and preventing gastric ulcer. The combined gastroprotective effect of tadalafil and limonene in the SNES formulation was evident through the histopathological examination of the pre-treated animal groups.

\section{Stability of SNES Tadalafil ODTs}

As presented in Table 6, there were non-significant differences in the physical characteristics, oral disintegration time, hardness, friability, and content uniformity between tablet samples, over 3 months of storage at 40 $\pm 2{ }^{\circ} \mathrm{C}$ and $75 \pm 5 \% \mathrm{RH}$ conditions, and those freshly prepared $(\mathrm{p}<0.05)$.

\section{Conclusion}

In the current study, the lyophilization of tadalafil-loaded limonene-based SNESs into ODTs was successfully applied to prepare optimal formulation (F6) with superior wetting time; $23.67 \mathrm{~s}$ with an outstanding disintegration time; $28 \mathrm{~s}$ and an accepted value of hardness; $3.11 \mathrm{~kg}$ / $\mathrm{cm}^{2}$ and $\%$ friability; $0.6 \%$. The in-vitro dissolution revealed a rapid initial phase with $68.5 \pm 0.03 \%$ within $10 \mathrm{~min}$. Tadalafil-loaded SNES ODTs and limonenebased SNES ODTs were in-vivo assessed for their gastroprotective effect on an ethanol-induced ulcer in male rats. Tadalafil-loaded as well as limonene ODTs demonstrated a gastroprotective effect with superior improvement in efficacy as compared to omeprazole. Histologically, the gastric mucosal integrity was ideally maintained with their combination. The overall results exposed that the SNES ODT formulation could be a promising approach for patients to benefit from the synergistic gastroprotective activity of the new nanocarrier-based system of PDE-5 inhibitor along with that of limonene oil in ODT formulation for geriatrics as an effective and safer avenue for the management of gastric ulcers.

\section{Disclosure}

The authors declare no conflicts of interest.

\section{References}

1. Mustafa M, Menon J, Muiandy R, Fredie R, Fariz A. Risk factors, diagnosis, and management of peptic ulcer disease. J Dent Med Sci. 2015;14(7):40-46. doi:10.9790/0853-14784046

2. Chen H, Liao H, Liu Y, et al. Protective effects of pogostone from Pogostemonis Herba against ethanol-induced gastric ulcer in rats. Fitoterapia. 2015;100:110-117. doi:10.1016/j.fitote.2014.11.017

3. Milosavljevic T, Kostić-Milosavljević M, Jovanović I, Krstić M. Complications of peptic ulcer disease. Dig Dis. 2011;29:491-493. doi:10.1159/000331517

4. Visser LE, Graatsma HH, Stricker BHC. Contraindicated NSAIDs are frequently prescribed to elderly patients with peptic ulcer disease. Br J Clin Pharmacol. 2002;53(2):183-188. doi:10.1046/j.0306-5251. 2001.01190.X

5. Cheng Y, Macera AC, Davis RD, Blair NS. Physical activity and peptic ulcers. West J Med. 2000;173(2):101-107. doi:10.1136/ewjm. 173.2.101

6. Boligona AA, Freitasa RB, de Bruma TF, et al. Antiulcerogenic activity of Scutia buxifolia on gastric ulcers induced by ethanol in rats. Acta Pharm B. 2014;4(5):358-367. doi:10.1016/j.apsb.2014.05. 001

7. Kim HU. Diagnostic and treatment approaches for refractory peptic ulcers. Clin Endosc. 2015;48:285-290. doi:10.5946/ce.2015.48.4.285

8. Jaynes M, Kumar AB. The risks of long-term use of proton pump inhibitors: a critical review. Ther Adv Drug Saf. 2019;10:1-13. doi:10.1177/2042098618809927

9. Gray SL, Lacroix AZ, Larson J, et al. Proton pump inhibitor use, hip fracture, and change in bone mineral density in postmenopausal women: results from the women's health initiative. Arch Intern Med. 2010;170(9):765-771. doi:10.1001/archinternmed.2010.94

10. Yang YX, Lewis JD, Epstein S, Metz DC. Long-term proton pump inhibitor therapy and risk of hip fracture. J Am Med Assoc. 2006;296 (24):2947-2953. doi:10.1001/jama.296.24.2947

11. O'Connell MB, Madden DM, Murray AM, Heaney RP, Kerzner LJ. Effects of proton pump inhibitors on calcium carbonate absorption in women: a randomized crossover trial. Am J Med. 2005;118 (7):778-781. doi:10.1016/j.amjmed.2005.02.007

12. Park JU, Abdur Rahman A, Hussain A, Cho JS, Lee YI, Kang JH. Gastroprotective effects of plants extracts on gastric mucosal injury in experimental sprague-dawley rats. Biomed Res Int. 2019;1-11. doi: $10.1155 / 2019 / 8759708$

13. Rozza AL, Moraes TM, Kushima H, et al. Gastroprotective mechanisms of Citrus lemon (Rutaceae) essential oil and its majority compounds limonene and -pinene: involvement of heat-shock protein-70, vasoactive intestinal peptide, glutathione, sulfhydryl compounds, nitric oxide and prostaglandin E2. Chem Biol Interact. 2011;189:82-89. doi:10.1016/j.cbi.2010.09.031

14. Mehannaa MM, Domiati S, Chmaisse HN, El Mallah A. Antinociceptive effect of tadalafil in various pain models: involvement of opioid receptors and nitric oxide cyclic GMP pathway. Toxicol Appl Pharmacol. 2018;352(May):170-175. doi:10.1016/j. taap.2018.05.013

15. Mostafa T. Non-sexual implications of phosphodiesterase type 5 inhibitors. Sex Med Rev. 2016;5:1-30. doi:10.1016/j.sxmr.2016.02. 004

16. Kolawole A, Francis SO. Effects of a type V phosphodiesterase inhibitor (tadalafil) on indomethacin-induced gastric ulceration in rats. Int J Trop Med. 2012;7(3):111-117. doi:10.3923/ijtmed.2012. 111.116 
17. Duffin R, Shaw CA, Rossi AG. Sildenafil reduces alcohol-induced gastric damage: just say "NO". Br J Pharmacol. 2008;153(4): 623-624. doi:10.1038/sj.bjp.0707642

18. Slavkova M, Breitkreutz J. Orodispersible drug formulations for children and elderly. Eur J Pharm Sci. 2015;75(March):2-9. doi:10.1016/j.ejps.2015.02.015

19. Al-Amodi YA, Hosny KM, Alharbi WS, Safo MK, El-Say KM. Investigating the potential of transmucosal delivery of febuxostat from oral lyophilized tablets loaded with a self-nanoemulsifying delivery system. Pharmaceutics. 2020;12(6):1-18. doi:10.3390/ pharmaceutics 12060534

20. El-Say KM, Ahmed TA, Ahmed OAA, Hosny KM, Abd-Allah FI. Self-nanoemulsifying lyophilized tablets (SNELTs) for flash oral transmucosal delivery of vitamin $\mathrm{K}$ : development and clinical evaluation. J Pharm Sci. 2017;106(9):2447-2456. doi:10.1016/j. xphs.2017.01.001

21. Refaat A, Sokar M, Ismail F, Boraei N. Tadalafil oral disintegrating tablets: an approach to enhance tadalafil dissolution. J Pharm Investig. 2015;45(5):481-491. doi:10.1007/s40005-015-0196-x

22. Mehanna MM, Mneimneh AT, Abed El Jalil K. Levofloxacin-loaded naturally occurring monoterpene-based nanoemulgel: a feasible efficient system to circumvent MRSA ocular infections. Drug Dev Ind Pharm. 2020;46(11):1787-1799. doi:10.1080/03639045.2020.1821048

23. Nasr AM, Gardouh AR, Ghonaim HM, Ghorab M. Design, formulation and in-vitro characterization of Irbesartan solid self-nanoemulsifying drug delivery system (S-SNEDDS) prepared using spray drying technique. J Chem Pharm Res. 2016;8(2):159-183.

24. Beg S, Swain S, Singh HP, Patra CN, Rao MB. Development, optimization, and characterization of solid self-nanoemulsifying drug delivery systems of valsartan using porous carriers. Am Assoc Pharm Sci. 2012;13(4):1416-1427. doi:10.1208/s12249012-9865-5

25. Yadav PS, Yadav E, Verma A, Amin S. Development, characterization, and pharmacodynamic evaluation of hydrochlorothiazide loaded self-nanoemulsifying drug delivery systems. Sci World J. 2014;2014:1-10. doi:10.1155/2014/274823

26. Saranya S, Chandrasekaran N, Mukherjee A. Antibacterial activity of eucalyptus oil nanoemulsion against Proteus mirabilis. Int J Pharm Pharm Sci. 2012;4(SUPPL 3):668-671.

27. Jeevana Jyothi B, Sreelakshmi K. Design and evaluation of self-nanoemulsifying drug delivery system of Flutamide. J Young Pharm. 2011;3(1):4-8. doi:10.4103/0975-1483.76413

28. Waters LJ, Hanrahan JP, Tobin JM, et al. Enhancing the dissolution of phenylbutazone using Syloid ${ }^{\circledR}$ based mesoporous silicas for oral equine applications. J Pharm Anal. 2018;8(3):181-186. doi:10.10 16/j.jpha.2018.01.004

29. Convention USP. The United States pharmacopeia 2014: USP 37; The national formulary: NF 32. United States pharmacopeial convention; 2012. Available from: https://books.google.com.lb/ books?id=7bqKwgEACAAJ. Accessed December 03, 2020.

30. Bandari S, Mittapalli RK, Gannu R, Rao YM. Orodispersible tablets: an overview. Asian J Pharm. 2008;2(1):2-11. doi:10.4103/09738398.41557

31. Zidan AS, Aljaeid BM, Mokhtar M, Shehata TM. Taste-masked orodispersible tablets of cyclosporine self-nanoemulsion lyophilized with dry silica. Pharm Dev Technol. 2015;20(6):652-661. doi:10.3109/ 10837450.2014.908307

32. Chrastina A, Baron VT, Abedinpour P, Rondeau G, Welsh J, Borgström P. Plumbagin-loaded nanoemulsion drug delivery formulation and evaluation of antiproliferative effect on prostate cancer cells. Biomed Res Int. 2018;2018:1-7. doi:10.1155/2018/9035452

33. Karakaya K, Hanci V, Bektas S, et al. Mitigation of indomethacin-induced gastric mucosal lesions by a potent specific type V phosphodiesterase inhibitor. World J Gastroenterol. 2009;15 (40):5091-5096. doi:10.3748/wjg.15.5091
34. Cheong AM, Tan ZW, Patrick NO, Nyam CPT, Lim YM, Lin K. Improvement of gastroprotective and anti-ulcer effect of kenaf seed oil-in-water nanoemulsions in rats. Food Sci Biotechnol. 2018;27 (4):1175-1184. doi:10.1007/s10068-018-0342-0

35. Qi X, Qin J, Ma N, Chou X, Wu Z. Solid self-microemulsifying dispersible tablets of celastrol: formulation development, characterization and bioavailability evaluation. Int J Pharm. 2014;472(1-2):40-47. doi:10.1016/j.ijpharm.2014.06.019

36. De Souza MC, Vieira AJ, Beserra FP, Pellizzon $\mathrm{CH}, \mathrm{N}^{\prime}$ obrega $\mathrm{RH}$, Rozza AL. Gastroprotective effect of limonene in rats: influence on oxidative stress, inflammation and gene expression. Phytomedicine. 2018;53:37-42. doi:10.1016/j.phymed.2018.09.027

37. Abou Zeit-har M, Verimer T, Long JP. No Title. Pharmazie. 1982;593-595.

38. Sabiu S, Garuba T, Sunmonu TO, Sulyman AO, Ismail NO. Indomethacin-induced gastric ulceration in rats: ameliorative roles of Spondias mombin and Ficus exasperata. Pharm Biol. 2016;54 (1):180-186. doi:10.3109/13880209.2015.1029050

39. Mehanna MM, Alwattar JK, Elmaradny HA. Optimization, physicochemical characterization and in vivo assessment of spray dried emulsion: a step toward bioavailability augmentation and gastric toxicity minimization. Int J Pharm. 2015;496(2):766-779. doi:10. 1016/j.ijpharm.2015.11.009

40. Pawar H, Varkhade C, Jadhav P, Mehra K. Development and evaluation of orodispersible tablets using a natural polysaccharide isolated from Cassia tora seeds. Integr Med Res. 2014;3(2):91-98. doi:10.1016/j.imr.2014.03.002

41. Mehanna MM, Motawaa AM, Samaha MW. Tadalafil inclusion in microporous silica as effective dissolution enhancer: optimization of loading procedure and molecular state characterization. J Pharm Sci. 2011;100(5):1805-1818. doi:10.1002/jps

42. Shakeel F, Faisal MS. Nanoemulsion: a promising tool for solubility and dissolution enhancement of celecoxib. Pharm Dev Technol. 2010;15(1):53-56. doi:10.3109/10837450902967954

43. Ali HH, Hussein AA. Oral nanoemulsions of candesartan cilexetil: formulation, characterization and in vitro drug release studies. Am Assoc Pharm Sci. 2017;3(4):1-16. doi:10.1186/ s41120-017-0016-7

44. Yi Z, Changguang W, Alert HLC, et al. Self-nanoemulsifying drug delivery system (SNEDDS) for oral delivery of Zedoary essential oil: formulation and bioavailability studies. Int J Pharm Pharm. 2010;383 (1-2):170-177. doi:10.1016/j.ijpharm.2009.08.035

45. Nasr A, Gardouh A, Ghorab M. Novel solid self-nanoemulsifying drug delivery system (S-SNEDDS) for oral delivery of olmesartan medoxomil: design, formulation, pharmacokinetic and bioavailability evaluation. Pharmaceutics. 2016;8:20. doi:10.3390/pharmaceutics 8030020

46. Moon-Jeong R, Clarence AM. Spontaneous emulsification of oils containing hydrocarbon, nonionic surfactant, and oleyl alcohol. J Colloid Interface Sci. 1999;209(1):179-192. doi:10.1006/jcis.1998.5865

47. Subramanian P, Siddalingam R. Self-nanoemulsifying drug delivery systems of poorly soluble drug dutasteride: formulation and in-vitro characterization. J Appl Pharm Sci. 2017;7(4):11-22. doi:10.7324/ JAPS.2017.70402

48. Dash R, Mohammed H, Touseef H, Devi R. Design, optimization and evaluation of glipizide solid self-nanoemulsifying drug delivery for enhanced solubility and dissolution. Saudi Pharm J. 2015;23:52 8-540. doi:10.1016/j.jsps.2015.01.024

49. Avachat AM, Patel VG. Self nanoemulsifying drug delivery system of stabilized ellagic acid - phospholipid complex with improved dissolution and permeability. Saudi Pharm J. 2015;23(3):276-289. doi:10.1016/j.jsps.2014.11.001

50. Malakar J, Nayak AK, Goswami S. Use of response surface methodology in the formulation and optimization of bisoprolol fumarate matrix tablets for sustained drug release. ISRN Pharm. 2012;2012 (December):1-10. doi:10.5402/2012/730624 
51. Bin LK, Peh KK. Investigation on the effect of polymer and starch on the tablet properties of lyophilized orally disintegrating tablet. Arch Pharm Res. 2015;1997. doi:10.1007/s12272-014-0542-y.

52. Chandrasekhar R, Hassan Z, AlHusban F, Smith AM, Mohammed AR. The role of formulation excipients in the development of lyophilised fast-disintegrating tablets. Eur J Pharm Biopharm. 2009;72(1):119-129. doi:10.1016/j.ejpb.2008.11.011

53. Djagny KB, Wang Z, Xu S. Gelatin: a valuable protein for food and pharmaceutical industries: review. Crit Rev Food Sci Nutr. 2001;41 (6):481-492. doi:10.1080/20014091091904

54. Hirani JJ, Rathod DA, Vadalia KR. Orally disintegrating tablets: a review. Trop J Pharm Res. 2009;8(2):161-172. doi:10.4314/tjpr. v8i2.44525

55. Rojas J, Guisao S, Ruge V. Functional assessment of four types of disintegrants and their effect on the spironolactone release properties. AAPS PharmSciTech. 2012;13(4):1054-1062. doi:10.1208/s12249012-9835-y

56. Desai PM, Er PXH, Liew CV, Heng PWS. Functionality of disintegrants and their mixtures in enabling fast disintegration of tablets by a quality by design approach. AAPS PharmSciTech. 2014;15 (5):1093-1104. doi:10.1208/s12249-014-0137-4

57. Mehanna MM, Motawaa AM, Samaha MW. In sight into tadalafil block copolymer binary solid dispersion: mechanistic investigation of dissolution enhancement. Int $J$ Pharm. 2010;402(1-2):78-88. doi:10.1016/j.ijpharm.2010.09.024

58. Dorota W, Krzak J, Macikowski B, Berkowski R. Evaluation of the release kinetics of a pharmacologically active substance from model intra-articular implants replacing the cruciate ligaments of the knee. MDPI:Materials. 2019;12(8):1-13. doi:10.3390/ma12081202
59. Alvarez-Suarez JM, Dekanski D, Ristić S, et al. Strawberry polyphenols attenuate ethanol-induced gastric lesions in rats by activation of antioxidant enzymes and attenuation of MDA increase. PLoS One. 2011;6(10):e25878. doi:10.1371/journal.pone.0025878

60. Chandranath S, Bastaki S, Singh J. A comparative study on the activity of lansoprazole, omeprazole and PD-136450 on acidified ethanol- and indomethacin-induced gastric lesions in the rat. Clin Exp Pharmacol Physiol. 2002;29(3):173-180. doi:10.1046/j.14401681.2002.03626.x

61. Guzmán-Gómez O, García-Rodríguez RV, Quevedo-Corona L, et al. Amelioration of ethanol induced gastric ulcers in rats pretreated with phycobiliproteins of arthrospira (Spirulina) maxima. Nutrients. 2018;10(6):1-15. doi:10.3390/nu10060763

62. Shin JM, Kim N. Pharmacokinetics and pharmacodynamics of the proton pump inhibitors. J Neurogastroenterol Motil. 2013;19 (1):25-35. doi:10.5056/jnm.2013.19.1.25

63. Yandrapu H, Sarosiek J. Protective factors of the gastric and duodenal mucosa: an overview protective factors of the gastric and duodenal mucosa: an overview. Curr Gastroenterol Rep. 2016;17(24):1-8. doi:10.1007/s11894-015-0452-2

64. Thabrew M, Arawwawala L. An overview of in vivo and in vitro models that can be used for evaluating anti-gastric ulcer potential of medicinal plants. Austin Biol. 2016;1(2):1-9.

65. Oliveira FA, Andrade LN, De Sousa ÉBV, De Sousa DP. Anti-ulcer activity of essential oil constituents. Molecules. 2014;19(5):57 17-5747. doi:10.3390/molecules19055717
International Journal of Nanomedicine

\section{Publish your work in this journal}

The International Journal of Nanomedicine is an international, peerreviewed journal focusing on the application of nanotechnology in diagnostics, therapeutics, and drug delivery systems throughout the biomedical field. This journal is indexed on PubMed Central, MedLine, CAS, SciSearch ${ }^{\mathbb{}}$, Current Contents ${ }^{\mathbb{R}} /$ Clinical Medicine, $^{2}$

\section{Dovepress}

Journal Citation Reports/Science Edition, EMBase, Scopus and the Elsevier Bibliographic databases. The manuscript management system is completely online and includes a very quick and fair peer-review system, which is all easy to use. Visit http://www.dovepress.com/ testimonials.php to read real quotes from published authors. 